\title{
Generalization Fixed Points of Multivalued $\alpha$-Admissible Mappings in 2-Metric Spaces
}

\author{
HANY A. ATIA ${ }^{1, *}$ MONA S. BAKRY ${ }^{2}$, AYA A. ABD-ELRASHED ${ }^{1}$ \\ ${ }^{1}$ Department of Mathematics, Fauclty of Science, Zagazig University, EGYPT \\ ${ }^{2}$ Department of Mathematics, Fauclty of Science, Tanta University, EGYPT
}

Abstract: - In this paper, we create some fixed-point results of multivalue $\alpha$-admissible of 2-metric spaces. We introduce Hausdorff distance in 2-metric space, use it in our theorem. we investigated the existence of some fixed point results for new types of contraction. We study the stability of fixed point set.

Key-Words: - Metric spaces, 2-metric spaces, multivalued $\alpha$-admissible mappings, fixed point, Hausdorff metric, $\alpha-\psi$-contraction.

Received: March 25, 2021. Revised: December 17, 2021. Accepted: January 10, 2021. Published: February 4, 2022.

\section{Introduction}

One of the most valuable findings is the popular Banach contraction mapping principle [1] in nonlinear analysis. It was used in many different mathematical branches and in the general physical sciences. Metric fixed-point theory developed in various directions by mathematicians over the years. A comprehensive account is provided of that development Kirk and Sims in the Handbook [2]. Extended the contraction mapping theory of Banach by the usage of a legal Contractive Situation by Dass and Gupta [3]. Abu-Donia establishes some fixed point theorems in some types of metric spaces [cf.4-8]. Aubin and Cellina discuss some elements of this research in their book [9]. Nadler[10] expanded the Banach principle of contraction to setvalued mappings by the Hausdorff metric. Driven by Nadler's results, much research is done on fixed points multi-valued functions were conducted using this Hausdorff metric in different directions by multiple authors [11-15]. Stability is a approach associated with the limiting attitude of a system. It has been studied in various contexts of discrete and continuous dynamical systems [16,17]. Studies of the relation between the convergence of a mapping sequence and its fixed Points, known as stability of fixed points, were also widely studied in different settings [18-20]. the set of fixed points of multivalued mappings becomes bigger and hence more important for the study of stability. In [21] Samet et al. presented the definition of $\alpha$-admissible mapping and a new group contractive mapping type known as $\alpha-\psi$-contractive mapping type.[21] Expansion and generalization of current fixed-point literature results, in fact, the Banach's contraction principle. In addition, Karapinar and Samet [22] widespreaded the $\alpha-\psi$-contractive type mappings and access assorted fixed point theorems for this generalized class of contractive mappings. Since then, fixed point results of $\alpha$-admissible mappings have been established, such as [23,24]..

The concepts from setvalued analysis that we use in this paper are as follows. Let $(X, d)$ be a metric space. Then

$$
N(X)=
$$

$\{A: A$ is a non empty subset of $X\}$,

$$
S(X)=
$$

$\{A: A$ is a non empty compact subset of $X\}$,

$$
B(X)=
$$

$\{A: A$ is a non empty bounded subset of $X\}$ and $S B(X)=$

$\{\mathrm{A}: \mathrm{A}$ is a non empty closed and bounded subset of $\mathrm{X}\}$.

For $x \in X$ and $B \in N(X)$, the function $D(x, B)$, and for $A, B \in S B(X)$, the function $H(A, B)$ are defined

as follows:

$$
D(x, B)=\inf \{d(x, y): y \in B\}
$$

and

$$
H(A, B)=\max \left\{\sup _{x \in A} D(x, B), \sup _{y \in B} D(y, A)\right\} .
$$

$H$ is established the Hausdorff metric induced by the metric $d$ on $S B(X)$ [23]. encourage, if $(X, d)$ is a complete then $S B(X), H$ is also complete.

The following lemma Nadler[18] generated by Nadler[18] 
Lemma 1.1 [18] Let $(X, d)$ be a metric space and $A, B \in S B(X)$. Let $q>1$. next for every $x \in A$, there exists $y \in B$ so that $d(x, y) \leq$ $q H(A, B)$.

In [18] Nadler certain that Lemma 1.1 is also accurate for $q \geq 1$, wherever $A, B \in S(X)$. Here we current the lemma

Lemma 1.2 [25] Let $(X, d)$ be a metric space and $A, B \in S B(X)$. Let $q \geq 1$. next for every $x \in A$, there exists $y \in B$ so that $d(x, y) \leq$ $q H(A, B)$.

The following is aftereffect of Lemma 1.2

Lemma 1.3 [25] Let two non-empty compact subsets of a metric space $(X, d)$ are $A$ and $B$ and $T$ is a multivalued mapping since $T: A \rightarrow S(B)$ Let $q \geq 1$. Next for $a, b \in A$ and $x \in T a$, there endure $y \in T b$ so that $d(x, y) \leq q H(T a, T b)$.

Definition 1.1 [21]. Let $T: X \rightarrow X$ and $\alpha: X \times$ $X \rightarrow[0, \infty)$ be a function. We express that $T$ is an $\alpha$-admissible mapping if $x, y \in X$,

$$
\alpha(x, y) \geq 1 \Longrightarrow \alpha(T x, T y) \geq 1 \text {. }
$$

In the following we characterize multivalued $\alpha$ admissible mapping. $N(X)$ in the interpretation stand for the collection of all nonempty subsets of a nonempty set $X$.

Definition 1.2 [25]. Let $T: X \rightarrow N(X)$ a multivalued mapping since $X$ is non-empty set and $\alpha: X \times X \rightarrow[0, \infty)$. For $x_{0}, y_{0} \in X$ the mapping $T$ called multivalued $\alpha$-admissible if $\alpha(x, y) \geq 1 \Rightarrow \alpha\left(x_{1}, y_{1}\right) \geq 1$ where $x_{1} \in T x_{0}$ and $y_{1} \in T y_{0}$.

Definition 1.3 [25]. Let $T: X \rightarrow S B(Y)$ be a multivalued mapping, since $(X, \sigma),(Y, d)$ are two metric spaces and $H$ is the Hausdorff metric on $S B(Y)$. The mapping $T$ is called continuous at $x \in X$ if for any sequence $\left\{x_{n}\right\}$ in $X$ and $H\left(T x, T x_{n}\right) \rightarrow 0$ when $\sigma\left(x, x_{n}\right) \rightarrow 0$ as $n \rightarrow \infty$

Definition 1.4 [25] Let $p: X \rightarrow X$ a singlevalued mapping, $T: X \rightarrow N(X)$ a multivalued mapping and $X$ is a non-empty set. A point $x \in$ $X$ is a fixed point of $p$ (resp. T) iff $x=p x$ (resp. $x \in T x$ ).

\section{Main Results}

for $x \in X$ and $B, C \in N(X)$, for $A, B$ and $C \in$ $S B(X)$ the functions

$$
\begin{aligned}
& \quad H(A, B, C) \\
& =\max \left\{\sup _{x \in A} D(x, B, C), \sup _{y \in B} D(y, A, C),\right. \\
& \text { where } \\
& \left.\qquad \sup _{z \in C} D(z, A, B)\right\}, \\
& \qquad(x, B, C)=\inf \{d(x, y, z): y \in B, z \in C\} .
\end{aligned}
$$

$H$ is known as the Hausdorff metric induced by the 2-metric $d$ on $S B(X)$.If $(X, d)$ is complete then $(S B(X), H)$ is also complete.

We established the following lemma.

Lemma 2.1 Let $(X, d)$ be a 2-metric space and $A, B$ and $C \in S B(X)$. Let $q \geq 1$. next for every $x \in A$, there exists $y \in B$ and $z \in C$ so that $d(x, y, z) \leq q H(A, B, C)$.

proof. Let $A, B$ and $C \in S(X)$. and $x \in A$. Since $A, B$ and $C \in S(X)$, the resultbis true if $q>1$. So, we shall prove the result for $q=1$. Now, we know that

$$
\begin{aligned}
& H(A, B, C) \\
& =\max \left\{\sup _{x \in A} D(x, B, C), \sup _{y \in B} D(y, A, C),\right. \\
& \left.\quad \sup _{z \in C} D(z, A, B)\right\} .
\end{aligned}
$$

From the definition,

$p=D(x, B, C)=\inf \{d(x, y, z): y \in B, z \in$

$C\} \leq H(A, B, C)$. Then there exists a sequence $\left\{y_{n}\right\}$ in $B$ such that $d\left(x, y_{n}, z\right) \rightarrow p$ as $n \rightarrow \infty$. Since $B$ is compact, $\left\{y_{n}\right\}$ has a convergent subsequence $\left\{y_{n(k)}\right\}$. Hunce there exists $y \in X$ such that $y_{n(k)} \rightarrow y$ as $k \rightarrow \infty$. As $B$ is compact, it is closed and $y \in B$. Now, $\lim _{n \rightarrow \infty} d\left(x, y_{n}, z\right)=p$

implies that $\lim _{k \rightarrow \infty} d\left(x, y_{n(k)}, z\right)=p$, that is, $d(x, y, z)=p=D(x, B, C) \leq H(A, B, C)$.

Hence the proof is completed.

the following is consequence of Lemma 2.1

Lemma 2.2 Let $A, B$ and $C$ are non-empty compact subsets of a 2-metric space $(X, d)$, where $R=B \cup C$ and $T$ is a multivalued mapping since $T: A \rightarrow S(R)$ Let $q \geq 1$. Next for $a, b$ and $c \in A, x \in T a$ there endure $y \in T b$ and $z \in T c$ so that $d(x, y, z) \leq q H(T a, T b, T c)$. 
Definition 2.1 Let $T: X \rightarrow X$ and $\alpha: X \times X \times$ $X \rightarrow[0, \infty)$ be a function. We say that $T$ is an $\alpha$-admissible mapping if $x, y, z \in X$,

$$
\alpha(x, y, z) \geq 1 \Rightarrow \alpha(T x, T y, T z) \geq 1 \text {. }
$$

Definition 2.2 Let $(X, d)$ be a 2-metric space and $T: X \rightarrow N(X)$ a multivalued mapping since $\alpha: X \times X \times X \rightarrow[0, \infty)$. For $x_{0}, y_{0}$ and $z_{0} \in X$ the mapping $T$ called multivalued $\alpha$-admissible if

$$
\alpha(x, y, z) \geq 1 \Rightarrow \alpha\left(x_{1}, y_{1}, z_{1}\right) \geq 1
$$

where $x_{1} \in T x_{0}, y_{1} \in T y_{0}$ and $z_{1} \in T z_{0}$

Definition 2.3 Let $(X, d),(Y, \sigma)$ are two 2metric spaces, $T: X \rightarrow S B(Y)$ and $H$ is the Hausdorff metric on $S B(Y)$. The mapping $T$ is said to be continuous at $x \in X$ if for any sequence $\left\{x_{n}\right\}$ in $X, H\left(T x, T x_{n}, T x_{n+1}\right) \rightarrow 0$ whenever $d\left(x, x_{n}, x_{n+1}\right) \rightarrow 0$ as $n \rightarrow \infty$.

Theorem 2.1 Let $(X, d)$ be a complete 2-metric space, $\alpha: X \times X \times X \rightarrow[0, \infty)$ and $T: X \rightarrow S(X)$ a multivalued mapping. Let $T$ be multivalued $\alpha$ admissible and continuous. Let $\psi:[0, \infty) \rightarrow$ $[0, \infty)$ be a nondecreasing function and continuos with $\sum_{n=1}^{\infty} \psi^{n}(t)<\infty$ and $\psi(t)<t$ for each $t>0$. Suppose that for all $x, y, z \in X$, $\alpha(x, y, z) H(T x, T y, T z) \leq$

$\psi\left(\max \left\{d(x, y, z), D\left(x, T x, T^{2} x\right), D\left(y, T y, T^{2} y\right)\right.\right.$,

$$
\begin{gathered}
\frac{D(x, y, T z)-D(x, z, T z)}{2}, \\
\frac{D\left(y, T y, T^{2} y\right)\left[1+D\left(x, T x, T^{2} x\right)\right]}{1+d(x, y, z)}, \\
\left.\left.\frac{D\left(z, T y, T^{2} x\right)\left[1+D\left(x, T y, T^{2} z\right)\right]}{1+d(x, y, z)}\right\}\right) .
\end{gathered}
$$

if there exist $x_{0} \in X, x_{1} \in T x_{0}$ and $x_{2} \in T x_{1}$ such that $\alpha\left(x_{0}, x_{1}, x_{2}\right) \geq 1$, then $T$ has a fixed point in $X$.

Proof From the condition, there exist $x_{0} \in$ $X, x_{1} \in T x_{0}$ and $x_{2} \in T x_{1}$ such that $\alpha\left(x_{0}, x_{1}, x_{2}\right) \geq 1$. By lemma 2.2, for $x_{2} \in T x_{1}$ there exists $x_{3} \in T x_{2}$ such that $d\left(x_{1}, x_{2}, x_{3}\right) \leq \alpha\left(x_{0}, x_{1}, x_{2}\right) H\left(T x_{0}, T x_{1}, T x_{2}\right)$. Employ (1) and applying the monotone property of $\psi$, we have

$$
\begin{aligned}
& d\left(x_{1}, x_{2}, x_{3}\right) \leq \alpha\left(x_{0}, x_{1}, x_{2}\right) H\left(T x_{0}, T x_{1}, T x_{2}\right) \\
& \leq \\
& \psi\left(\operatorname { m a x } \left\{d\left(x_{0}, x_{1}, x_{2}\right), D\left(x_{0}, T x_{0}, T^{2} x_{0}\right),\right.\right. \\
& D\left(x_{1}, T x_{1}, T^{2} x_{1}\right) \\
& \frac{D\left(x_{0}, x_{1}, T x_{2}\right)-D\left(x_{0}, x_{2}, T x_{2}\right)}{2}, \\
& \frac{D\left(x_{1}, T x_{1}, T^{2} x_{1}\right)\left[1+D\left(x_{0}, T x_{0}, T^{2} x_{0}\right)\right]}{1+d\left(x_{0}, x_{1}, x_{2}\right)}, \\
& \left.\left.\frac{D\left(x_{2}, T x_{1}, T^{2} x_{0}\right)\left[1+D\left(x_{0}, T x_{1}, T^{2} x_{2}\right)\right]}{1+d\left(x_{0}, x_{1}, x_{2}\right)}\right\}\right) \\
& \leq \psi\left(\operatorname { m a x } \left\{d\left(x_{0}, x_{1}, x_{2}\right), d\left(x_{0}, x_{1}, x_{2}\right),\right.\right. \\
& d\left(x_{1}, x_{2}, x_{3}\right) \text {, } \\
& \frac{d\left(x_{0}, x_{1}, x_{3}\right)-d\left(x_{0}, x_{2}, x_{3}\right)}{2} \\
& \frac{d\left(x_{1}, x_{2}, x_{3}\right)\left[1+d\left(x_{0}, x_{1}, x_{2}\right)\right]}{1+d\left(x_{0}, x_{1}, x_{2}\right)}, \\
& \left.\left.\frac{d\left(x_{2}, x_{2}, x_{2}\right)\left[1+d\left(x_{0}, x_{2}, x_{4}\right)\right]}{1+d\left(x_{0}, x_{1}, x_{2}\right)}\right\}\right) \\
& \leq \psi\left(\operatorname { m a x } \left\{d\left(x_{0}, x_{1}, x_{2}\right), d\left(x_{1}, x_{2}, x_{3}\right)\right.\right. \text {, } \\
& d\left(x_{0}, x_{1}, x_{2}\right)+d\left(x_{0}, x_{2}, x_{3}\right)+ \\
& \left.\left.\frac{d\left(x_{1}, x_{2}, x_{3}\right)-d\left(x_{0}, x_{2}, x_{3}\right)}{2}\right\}\right) \\
& \leq \psi\left(\max \left\{d\left(x_{0}, x_{1}, x_{2}\right), d\left(x_{1}, x_{2}, x_{3}\right)\right\}\right) \text {. }
\end{aligned}
$$

It follows that

$$
\begin{gathered}
d\left(x_{1}, x_{2}, x_{3}\right) \\
\leq \psi\left(\max \left\{d\left(x_{0}, x_{1}, x_{2}\right), d\left(x_{1}, x_{2}, x_{3}\right)\right\}\right) .
\end{gathered}
$$

Now,if

$\max \left\{d\left(x_{0}, x_{1}, x_{2}\right), d\left(x_{1}, x_{2}, x_{3}\right)\right\}=$ $d\left(x_{1}, x_{2}, x_{3}\right)$

Then from (2) and property of $\psi$ $d\left(x_{1}, x_{2}, x_{3}\right) \leq \psi\left(d\left(x_{1}, x_{2}, x_{3}\right)<d\left(x_{1}, x_{2}, x_{3}\right)\right.$,

which is a contradiction. Hence $d\left(x_{1}, x_{2}, x_{3}\right) \leq d\left(x_{0}, x_{1}, x_{2}\right)$. Then from (2), we have

$$
d\left(x_{1}, x_{2}, x_{3}\right) \leq \psi d\left(x_{0}, x_{1}, x_{2}\right)
$$

Since $x_{1} \in T x_{0}, x_{2} \in T x_{1}$ and $x_{3} \in T x_{2}$ and $\alpha\left(x_{0}, x_{1}, x_{2}\right) \geq 1$, the $\alpha$-admissibility of $T$ implies that $\alpha\left(x_{1}, x_{2}, x_{3}\right) \geq 1$. By Lemma (2.2), for $x_{3} \in T x_{2}$ there exists $x_{4} \in T x_{3}$ such that

$$
\begin{gathered}
d\left(x_{2}, x_{3}, x_{4}\right) \\
\leq \alpha\left(x_{1}, x_{2}, x_{3}\right) H\left(T x_{1}, T x_{2}, T x_{3}\right) .
\end{gathered}
$$


employ (1) and using the monotone property of $\psi$, we have

$$
\begin{gathered}
d\left(x_{2}, x_{3}, x_{4}\right) \leq \alpha\left(x_{1}, x_{2}, x_{3}\right) H\left(T x_{1}, T x_{2}, T x_{3}\right) \\
\leq \psi\left(\operatorname { m a x } \left\{d\left(x_{1}, x_{2}, x_{3}\right), D\left(x_{1}, T x_{1}, T^{2} x_{1}\right),\right.\right. \\
D\left(x_{2}, T x_{2}, T^{2} x_{2}\right), \\
\frac{D\left(x_{1}, x_{2}, T x_{3}\right)-D\left(x_{1}, x_{3}, T x_{3}\right)}{2}, \\
\frac{D\left(x_{2}, T x_{2}, T^{2} x_{2}\right)\left[1+D\left(x_{1}, T x_{1}, T^{2} x_{1}\right)\right]}{1+d\left(x_{1}, x_{2}, x_{3}\right)}, \\
\left.\left.\frac{D\left(x_{3}, T x_{2}, T^{2} x_{1}\right)\left[1+D\left(x_{1}, T x_{2}, T^{2} x_{3}\right)\right]}{1+d\left(x_{1}, x_{2}, x_{3}\right)}\right\}\right) \\
\leq \psi\left(\operatorname { m a x } \left\{d\left(x_{1}, x_{2}, x_{3}\right), d\left(x_{1}, x_{2}, x_{3}\right),\right.\right. \\
d\left(x_{2}, x_{3}, x_{4}\right), \frac{d\left(x_{1}, x_{2}, x_{4}\right)-d\left(x_{1}, x_{3}, x_{4}\right)}{2}, \\
\frac{d\left(x_{2}, x_{3}, x_{4}\right)\left[1+d\left(x_{1}, x_{2}, x_{3}\right)\right]}{1+d\left(x_{1}, x_{2}, x_{3}\right)}, \\
\left.\left.\quad \frac{d\left(x_{3}, x_{3}, x_{3}\right)\left[1+d\left(x_{1}, x_{3}, x_{5}\right)\right]}{1+d\left(x_{1}, x_{2}, x_{3}\right)}\right\}\right) \\
\leq \psi\left(\operatorname { m a x } \left\{d\left(x_{1}, x_{2}, x_{3}\right), d\left(x_{2}, x_{3}, x_{4}\right),\right.\right. \\
d\left(x_{1}, x_{2}, x_{3}\right)+d\left(x_{1}, x_{3}, x_{4}\right)+ \\
\left.\left.\frac{d\left(x_{2}, x_{3}, x_{4}\right)-d\left(x_{1}, x_{3}, x_{4}\right)}{2}\right\}\right) \\
\leq \quad
\end{gathered}
$$

$\psi\left(\max \left\{d\left(x_{1}, x_{2}, x_{3}\right), d\left(x_{2}, x_{3}, x_{4}\right)\right\}\right)$.

Suppose that $d\left(x_{1}, x_{2}, x_{3}\right)<d\left(x_{2}, x_{3}, x_{4}\right)$. Then $d\left(x_{2}, x_{3}, x_{4}\right) \neq 0$ and it folows by (4) and property of $\psi$ that

$$
\begin{aligned}
d\left(x_{2}, x_{3}, x_{4}\right) & \leq \psi\left(d\left(x_{2}, x_{3}, x_{4}\right)\right) \\
& <d\left(x_{2}, x_{3}, x_{4}\right),
\end{aligned}
$$

which is a contradiction. Then from (4) we have

$$
d\left(x_{2}, x_{3}, x_{4}\right) \leq \psi\left(d\left(x_{1}, x_{2}, x_{3}\right)\right) .
$$

Since $x_{2} \in T x_{1}, x_{3} \in T x_{2}$ and $x_{4} \in T x_{3}$ and $\alpha\left(x_{1}, x_{2}, x_{3}\right) \geq 1$, the $\alpha$-admissibility of $T$ implies that $\alpha\left(x_{2},\left.x\right|_{3}, x_{4}\right) \geq 1$. Continuing this process, we build up a sequence $\left\{x_{n}\right\}$ such that for all $n \geq 0$

$$
\begin{gathered}
x_{n+1} \in T x_{n}, \\
\alpha\left(x_{n}, x_{n+1}, x_{n+2}\right) \geq 1,
\end{gathered}
$$

and

$$
\begin{aligned}
& d\left(x_{n+1}, x_{n+2}, x_{n+3}\right) \\
& \leq \psi\left(d\left(x_{n}, x_{n+1}, x_{n+2}\right)\right)
\end{aligned}
$$

By copied operation (8) and monotone property of $\psi$, we have

$$
\begin{aligned}
d\left(x_{n+1}, x_{n+2},\right. & \left.x_{n+3}\right) \\
& \leq \psi\left(d\left(x_{n}, x_{n+1}, x_{n+2}\right)\right) \\
& \leq \psi^{2}\left(d\left(x_{n-1}, x_{n}, x_{n+1}\right)\right) \leq \ldots \\
& \leq \psi^{n+1}\left(d\left(x_{0}, x_{1}, x_{2}\right)\right)
\end{aligned}
$$

Then by a property of $\psi$, we have

$$
\begin{aligned}
& \sum_{n} d\left(x_{n}, x_{n+1}, x_{n+2}\right) \\
& \leq \sum_{n} \psi^{n}\left(d\left(x_{0}, x_{1}, x_{2}\right)\right)<\infty .
\end{aligned}
$$

This appearance that $\left\{x_{n}\right\}$ is a Cauchy sequence. From the completness of $X$, there exists $z \in X$ such that

$$
x_{n} \rightarrow z \text { as } n \rightarrow \infty .
$$

Since $x_{n+1} \in T x_{n}$, we have

$$
D\left(x_{n+2}, x_{n+1}, T z\right) \leq H\left(T x_{n+1}, T x_{n}, T z\right) .
$$

Taking limit as $n \rightarrow \infty$ in the raised inequality, and accepting (9) and the continuity of $T$, we have

$$
\begin{gathered}
D\left(z, z^{4}, D z\right)=\lim _{n \rightarrow \infty} D\left(x_{n+2}, x_{n+1}, T z\right) \leq \\
\lim _{n \rightarrow \infty} H\left(T x_{n+1}, T x_{n}, T z\right)=0, \\
\text { that is, } D(z, z, T z)=0 .
\end{gathered}
$$

Since $T z \in S(x), T z$ is compact and hence $T z$ is closed, that is, $T z=\overline{T z}$, where $\overline{T z}$ denotes the closure of $T z$. Now, $D(z, z, T z)=0$ implies that $z \in \overline{T z}=T z$, that is, $z$ is a fixed point ot $T$.

Theorem 2.2 Let $(X, d)$ be a 2-metric space, $T_{i}: X \rightarrow S(X), \quad i=1,2$ be two multivalued mapping and $\alpha: X \times X \times X \rightarrow[0, \infty)$. Let each $T_{i}, i=1,2$ be continuous and multivalued $\alpha$ admissible. Let $\psi:[0, \infty) \rightarrow[0, \infty)$ be a continuous and nondecreasing function with $\Phi(t)=\sum_{n=1}^{\infty} \psi^{n}(t)<\infty, \Phi(t) \rightarrow 0$ as $t \rightarrow 0$ and $\psi(t)<t$ for each $t>0$. Suppose that

(i) each $T_{i}, i=1,2$ satisfing (1), that is, for all $x, y$ and $z \in X$,

$$
\begin{gathered}
\alpha(x, y, z) H\left(T_{i} x, T_{i} y, T_{i} z\right) \leq \\
\psi\left(\operatorname { m a x } \left\{d(x, y, z), D\left(x, T_{i} x, T_{i}^{2} x\right), D\left(y, T_{i} y, T_{i}^{2} y\right),\right.\right. \\
\frac{D\left(x, y, T_{i} z\right)-D\left(x, z, T_{i} z\right)}{2},
\end{gathered}
$$




$$
\begin{aligned}
& \frac{D\left(y, T_{i} y, T_{i}^{2} y\right)\left[1+D\left(x, T_{i} x, T_{i}^{2} x\right)\right]}{1+d(x, y, z)} \\
& \left.\left.\frac{D\left(z, T_{i} y, T_{i}^{2} x\right)\left[1+D\left(x, T_{i} y, T_{i}^{2} z\right)\right]}{1+d(x, y, z)}\right\}\right)
\end{aligned}
$$

(ii) for any $x \in F\left(T_{1}\right)$,and $y \in T_{2} x$, we have $\alpha(x, y, z) \geq 1$ whenever $z \in T_{3} x$; and for any $x \in F\left(T_{2}\right)$ and $y \in T_{1} x$, we have $\alpha(x, y, z) \geq 1$ whenever $z \in T_{3} x$.

Then $H\left(F\left(T_{1}\right), F\left(T_{2}\right), F\left(T_{3}\right)\right) \leq \Phi(w)$, where $w=\sup _{x \in X} H\left(T_{1} x, T_{2} x, T_{3} x\right)$.

Proof From Theorem 2.1, the set of fixed point of $T_{i}(i=1,2)$ are non-empty, that is, $F\left(T_{i}\right) \neq$ $\emptyset$, for $i=1,2$. Let $y_{0} \in F\left(T_{1}\right)$, that is, $y_{0} \in$ $T_{1} y_{0}$. Then by Lemma 2.1, there exists $y_{1} \in$ $T_{2} y_{0}$ and $y_{2} \in T_{3} y_{0}$ such that

$d\left(y_{0}, y_{1}, y_{2}\right) \leq H\left(T_{1} y_{0}, T_{2} y_{0}, T_{3} y_{0}\right)$

Since $y_{0} \in F\left(T_{1}\right), y_{1} \in T_{2} y_{0}$ and $y_{2} \in T_{3} y_{0}$, by condition (ii), we have $\alpha\left(y_{0}, y_{1}, y_{2}\right) \geq 1$. By lemma 2.2, for $y_{1} \in T_{2} y_{0}, y_{2} \in T_{2} y_{1}$ there exists $y_{3} \in T_{2} y_{2}$ such that

$$
d\left(y_{1}, y_{2}, y_{3}\right) \leq
$$

$\alpha\left(y_{0}, y_{1}, y_{2}\right) H\left(T_{2} y_{0}, T_{2} y_{1}, T_{2} y_{2}\right)$.

Then contend similarly as in the proof of Theorem 2.1, we construct a sequence $y_{n}$ such that for all $n \geq 0$

$$
\begin{gathered}
y_{n+1} \in T_{2} y_{n} \\
\alpha\left(y_{n}, y_{n+1} y_{n+2}\right) \geq 1, \\
d\left(y_{n+1}, y_{n+2}, y_{n+3}\right) \\
\leq \psi\left(d\left(y_{n}, y_{n+1}, y_{n+} 2\right)\right)
\end{gathered}
$$

and

$$
\begin{gathered}
d\left(y_{n+1}, y_{n+2}, y_{n+3}\right) \leq \psi\left(d\left(y_{n}, y_{n+1}, y_{n+2}\right)\right) \\
\leq \psi^{2}\left(d\left(y_{n-1}, y_{n}, y_{n+1}\right)\right) \leq \ldots \\
\leq \psi^{n+1}\left(d\left(y_{0}, y_{1}, y_{2}\right)\right) .
\end{gathered}
$$

Contend similarly as in the proof of Theorem 2.1 , we prove that $\left\{y_{n}\right\}$ is a Cauchy sequence $X$ and there exists $v \in X$ such that

$$
y_{n} \rightarrow v \text { as } n \rightarrow \infty,
$$

further $\mathrm{v}$ is a fixed point of $T_{2}$, that is, $v \in T_{2} v$.
Now, from (10) and the definition of $w$, we have

$d\left(y_{0}, y_{1}, y_{2}\right) \leq H\left(T_{1} y_{0}, T_{2} y_{0}, T_{3} y_{0}\right) \leq w$

$=\sup _{x \in X} H\left(T_{1} x, T_{2} x, T_{3} x\right)$.

Repeatedly, by the triangle inequality and using (14), we have

$$
\begin{aligned}
& d\left(y_{0}, y_{1}, v\right) \leq \sum_{i=0}^{n}\left(d\left(y_{i}, y_{i+1}, y_{i+2}\right)\right) \\
&+d\left(y_{n}, y_{n+2}, v\right) \\
&+d\left(y_{n+1}, y_{n+2}, v\right) \\
& \leq \sum_{i=0}^{n} \psi^{i}\left(d\left(y_{0}, y_{1}, y_{2}\right)\right)+ \\
& d\left(y_{n}, y_{n+2}, v+d\left(y_{n+1}, y_{n+2}, v\right) .\right.
\end{aligned}
$$

Taking limit $n \rightarrow \infty$ in the above inequality, using (15),(16) and the propertyies of $\psi$, we have

$$
\begin{aligned}
& d\left(y_{0}, y_{1}, v\right) \leq \sum_{i=0}^{\infty} \psi^{i}\left(d\left(y_{0}, y_{1}, y_{2}\right)\right) \leq \\
& \sum_{i-0}^{\infty} \psi^{i}(w)=\Phi(w) .
\end{aligned}
$$

Thus, given arbitrary $y_{0} \in F\left(T_{1}\right)$, we can find $v \in F\left(T_{2}\right)$ for which

$$
d\left(y_{0}, y_{1}, v\right) \leq \Phi(w) .
$$

Similarly, we can prove that for arbitrary $c_{0} \in$ $F\left(T_{2}\right)$, there exists a $p \in F\left(T_{1}\right)$ such that $d\left(c_{0}, c_{1}, p\right) \leq \Phi(w)$. Hence, we conclude that $H\left(F\left(T_{1}\right), F\left(T_{2}, F\left(T_{3}\right)\right)\right) \leq \Phi(w)$.

\section{Conclusion}

In this paper we established the existence of fixed points of multivalued $\alpha$-admissible mappings in 2metric spaces. and we investigated the stability of fixed point, also we introduced and studied the notion of multivalued $\alpha$-admissible in 2-metric spaces

\section{References:}

[1] Banach, S.: Sur les oprations dans les ensembles abstraits et leurs applications aux quations intgrales. Fund. Math. 3, 133-181 (1922).

[2] Kirk, W.A., Sims, B.: Handbook of Metric Fixed Point Theory. Springer, Netherlands (2001).

[3] Dass, B.K., Gupta, S.: An extension of Banach contraction principle through 
rational expressions. Indian J. Pure Appl. Math. 6, 1455-1458 (1975).

[4] Abu-Donia, H. M., Atia, H. A., Khater, O. M. "Fixed point theorem by using $\psi$ contraction and $(\psi, \phi)$-contraction in probabilistic 2-metric spaces". Alexandria Engineering Journal 59(3)(2020), pp.12391242.

[5] Abu-Donia, H. M., Atia, H. A., Khater, O. M. "Common fixed point theorems in intuitionistic fuzzy metric spaces and intuitionistic $(\varphi, \psi)$-contractive mappings". Journal of Nonlinear Sciences and Applications (JNSA), 13(6)(2020).

[6] Abu-Donia, H. M., Atia, H. A., Khater, O. M. "Some fixed point theorems in fuzzy 2metric spaces under $\psi$-contractive mappings". Numerical and Computational Methods in Sciences and Engineering 2(1)(2020), pp.11-15.

[7] Abu-Donia, H. M., Atia, H. A., Khater, O. M. "Fixed point theorem in intuitionistic fuzzy 3-metric spaces under strict contractive conditions". Applied Mathematics and Information Sciences. 14(6)(2020), pp1-5.

[8] Abu-Donia, H. M., Atia, H. A., Khater, O. M. "Fixed point theorems for compatible mappings in intuitionistic fuzzy 3-metric spaces". Thermal Science, 24 (Suppl. 1), 371-376.

[9] Aubin, J.P., Cellina, A.: Differential inclusions multivalued maps and viability theory. Springer, Berlin(1984)

[10] Nadler Jr, S.B.: Multivalued contraction mapping. Pac. J. Math. 30, 475-488 (1969).

[11] Ćirić, L.B., Ume, J.S.: Some common fixed point theorems for weakly compatible mappings. J. Math. Anal. Appl. 314, 488499 (2006).

[12] Fakhar, M.: Endpoints of set-valued asymptotic contractions in metric spaces. Appl. Math. Lett. 24,428-431 (2011).

[13] Goebel, K., Kirk, W.A.: Topics in Metric Fixed Point Theory. Cambridge Studies in Advanced Mathematics. Cambridge University Press, Cambridge (1990).

[14] Gordji, M.E., Baghani, H., Khodaei, H., Ramezani, M.: A generalization of Nadler's fixed point theorem. J. Nonlinear Sci. Appl. 3, 148-151 (2010).

[15] Harandi, A.A.: End points of setvalued contractions in metric spaces.Nonlinear Anal. 72, 132-134 (2010).

[16] Robinson, C.: Dynamical Systems: Stability, Symbolic Dynamics, and Chaos, 2nd edn. CRC Press, Boca Raton (1998).

[17] Strogatz, S.: Nonlinear Dynamics and Chaos: With Applications to Physics, Biology, Chemistry, and Engineering. Westview Press, Boulder (2001).

[18] Lim, T.C.: Fixed point stability for set valued contractive mappings with applications to generalized differential equations. J. Math. Anal. Appl. 110, 436441 (1985).

[19] Markin, J.T.: A fixed point stability theorem for nonexpansive set valued mappings. J. Math. Anal. Appl. 54, 441-443 (1976).

[20] Nadler Jr, S.B.: Sequences of contractions and fixed points. Pac. J. Math. 27, 579-585 (1968).

[21] Samet, B.,Vetro, C.,Vetro, P.: Fixed point theorems for $\alpha-\psi$-contractive type mappings.Nonlinear Anal. 75, 2154-2165 (2012).

[22] Karapinar, E., Samet, B.: Generalized $\alpha-\psi$ contractive type mappings and related fixed point theorems with applications. Abstr. Appl. Anal. 2012, Article ID 793486 (2012).

[23] Karapinar, E., Agarwal, R.P.: A note on 'Coupled fixed point theorems for $\alpha-\psi$ contractive-type mappings in partially ordered metric spaces. Fixed Point Theory Appl. 2013, 216 (2013).

[24] Salimi, P., Latif, A., Hussain, N.: Modified $\alpha-\psi$-contractive mappings with applications. Fixed Point Theory Appl. 2013, 151 (2013).

[25] Choudhury, B.S., Metiya, N., Bandyopadhyay, c.:Fixed points of multivalued $\alpha$-admissible mappings. Rend. Circ. Mat. Palermo (2015) 64:43-55.

Creative Commons Attribution License 4.0 (Attribution 4.0 International, CC BY 4.0)

This article is published under the terms of the Creative Commons Attribution License 4.0 https://creativecommons.org/licenses/by/4.0/deed.en US 